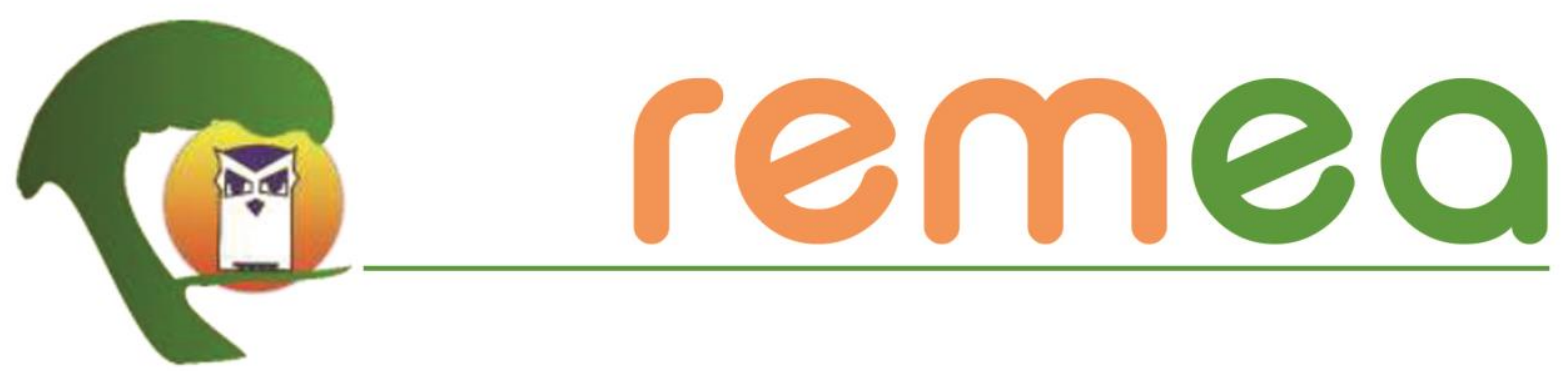

\title{
A dança das mulheres e $o$ artesanato Terena como referência para uma Educação Ambiental Decolonial ${ }^{1}$
}

\author{
Elisangela Castedo Maria do Nascimento ${ }^{2}$ \\ Secretaria Estadual de Educação de Mato Grosso do Sul \\ ORCID: https://orcid.org/0000-0002-8448-3315 \\ Heitor Queiroz de Medeiros ${ }^{3}$ \\ Universidade Católica Dom Bosco \\ ORCID: https://orcid.org/0000-0001-5313-1811
}

Resumo: Sipúterena é a dança das mulheres Terena. No passado, elas dançavam para dar boas-vindas aos guerreiros que chegavam da guerra. A dança das mulheres é carregada de significados, os costumes que antecedem a apresentação estão intimamente ligados à natureza. O objetivo neste artigo é mostrar o significado e a relação do artesanato e da dança Sipúterena com a natureza e como podem contribuir para a Educação Ambiental. Além das questões sociais, a dança nos proporcionou pensar e aprender mais sobre as questões ambientais e a utilização dos recursos. Suas práticas culturais e pedagógicas estão cheias de conceitos biológicos e ecológicos que podemos empregar na discussão de uma Educação Ambiental decolonial.

Palavras-chave: Dança das mulheres, Artesanato, Natureza.

\section{Danza de mujeres y artesanía terena como referente para la Educación Ambiental Decolonial}

Resumen: Sipúterena es el baile de las mujeres Terena. En el pasado, bailaban para dar la bienvenida a los guerreros que llegaban de la guerra. La danza de las mujeres está cargada de significados, las costumbres que preceden a la actuación están íntimamente ligadas a la naturaleza. El propósito de este artículo es mostrar el significado y la relación de la artesanía y la danza Sipúterena con la naturaleza y cómo pueden contribuir a la Educación Ambiental. Además de los temas sociales, la danza nos ha permitido pensar y aprender más sobre temas ambientales y el uso de recursos. Sus prácticas culturales y pedagógicas están llenas de conceptos biológicos y ecológicos que podemos utilizar en la discusión de una Educación Ambiental descolonial.

Palabras-clave: Danza de mujeres, Artesanía, Naturaleza.

\footnotetext{
${ }^{1}$ O presente trabalho foi realizado com apoio da Coordenação de Aperfeiçoamento de Pessoal de Nível Superior - Brasil (CAPES) - Código de Financiamento 001.

2 Doutora em Educação (UCDB), Mestre em Ensino de Ciências (UFMS), Especialista em Manejo de Recursos Naturais (UFMS), Graduada em Biologia, foi Bolsista CAPES/PROSUC de 2017 a 2020. Professora da Rede Estadual de Ensino, ecmcastedo@gmail.com

${ }^{3}$ Doutor em Ciências - Ecologia e Recursos Naturais (UFSCar), Mestre em Ciência Ambiental (USP), Graduado em História (UFMT), Professor do Programa de Pós-Graduação em Educação (UCDB), heitor.medeiros@ucdb.br
} 


\title{
Women's dance and Terena handicrafts as a reference for Decolonial Environmental Education
}

\begin{abstract}
Sipúterena is the dance of the Terena women. In the past, they danced to welcome warriors who arrived from the war. The women's dance is loaded with meanings, the customs that precede the performance are closely linked to nature. The purpose of this article is to show the meaning and the relationship of Sipúterena handicrafts and dance with nature and how they can contribute to Environmental Education. In addition to social issues, dance has enabled us to think and learn more about environmental issues and the use of resources. Its cultural and pedagogical practices are full of biological and ecological concepts that we can use in the discussion of a decolonial Environmental Education.
\end{abstract}

Keywords: Women's dance, Crafts, Nature.

\section{Introdução}

Este artigo é um dos resultados da produção de dados da pesquisa de doutorado iniciada em 2017, no Programa de Pós-Graduação em Educação pela Universidade Dom Bosco, com o tema de pesquisa: "Saberes indígenas e Educação Ambiental: Aprendendo com os Terena da aldeia Lagoinha no município de Aquidauana, Mato Grosso do Sul".

Como o objetivo da pesquisa foi aprender com os Terena, mergulhamos na cultura para compreender seus saberes, hábitos, rituais, religião, danças, artesanatos e como tudo isso está relacionado com a Natureza a partir de sua cosmologia.

Partindo desse entendimento que a cultura é subjetiva porque depende das representações e significados produzidos socialmente, entendemos que cada povo ou sociedade possui seus próprios significados, representações e correlações que o torna único. Dessa forma, o objetivo neste artigo é mostrar o significado e a relação do artesanato e da dança Sipúterena com a natureza e como podem contribuir para a Educação Ambiental. Na busca desse entendimento, utilizamos como ferramenta de pesquisa, a entrevista, observação e prática de todas as fases que antecedem a festa onde a dança é apresentada e o artesanato utilizado como adorno.

É importante explicar que os Terena possuem uma dança masculina e uma feminina, no entanto, decidimos abordar somente a feminina porque há pouca informação registrada, ao contrário da masculina, que é muito debatida e pesquisada na literatura que aborda a cultura Terena.

\section{Fundamentação teórica}


Na busca de compreender essa relação do Terena com a natureza encontramos apoio teórico/metodológico nas Teorias Pós, e no Grupo Modernidade/Colonialidade, que fazem a crítica aos modelos de conhecimento impostos pela modernidade como únicos e verdadeiros, subalternizando os demais conhecimentos, colocando-os à margem como inferiores e sem valor. A colonialidade, é interpretada, refletida e criticada pelos campos teóricos "Pós", que trazem propostas de metodologias, instrumentos e pedagogias decoloniais, revisando "as pedagogias nacionalistas ou nativistas que estabelecem a relação do Terceiro Mundo com o Primeiro Mundo em uma estrutura binaria de oposição" (BHABHA, 1998, p. 241).

O grupo Modernidade/Colonialidade (M/C) afirmam a partir do conceito de colonialidade de poder desenvolvido por Aníbal Quijano (2000), que ainda existem relações de colonialidade nos setores econômicos e políticos mesmo com o fim do colonialismo territorial (BALLESTRIN, 2013). Entender o conceito de colonialidade do poder, nos faz compreender que a visão de raça e racismo é quem organiza e estrutura e as hierarquias dos sistemas mundiais, visto que, "[...] organizou e continua organizando a diferença colonial, a periferia como natureza" (MIGNOLO, 2005, p. 34).

Foi a partir da teoria pós-colonial que se iniciou uma análise de como as narrativas dominantes constroem o sujeito subalterno, o outro enquanto objeto. Já nas escritas dos colonizados é analisada a narrativa de resistência ao poder imperial (SILVA, 2004). Neste sentido, a teoria pós-colonial nos faz refletir a partir do passado, as relações de poder do império sobre a colônia, e em nosso caso, nos aspectos ambientais, visto que, as colônias sempre foram tidas como locais de exploração de recursos naturais e minerais, pois nessa época a ciência estava em expansão e a lógica racional dizia que a natureza deveria ser explorada e dominada. Tristão (2014, p. 478) compreende que a teoria pós-colonial traz contribuição significativa ao campo da Educação Ambiental pois:

[...] trata-se de uma forma de compreender as relações cultura e meio ambiente local/global, com uma contribuição fundamental para rever os pressupostos da lógica determinista e da proposta oficial de políticas internacionais que nos conduzem, da mesma maneira, a uma educação para o desenvolvimento sustentável, por exemplo, com repercussão de um discurso consensual para a preservação e proteção da natureza. 
A EA inspirada na teoria pós-colonial, está partindo para desenvolver a decolonialidade, por caminhos alternativos das relações de poder, de colonização e submissão entre culturas e nações (TRISTÃO, 2014). A decolonialidade visa compreender a cultura, o imperialismo e suas influências, é uma forma de contestar e destituir "as estruturas sociais, políticas e epistêmicas da colonialidade" (WALSH, 2009, p. 24), que possui padrões de poder fixados na racialização, na inferiorização, na desumanização e no conhecimento eurocêntrico hegemônico.

Dessa forma, as teorias Pós-Coloniais, nos possibilitaram fazer análises outras da relação sustentável do indígena no meio ambiente, assim como compreender de que maneira sua cosmologia organiza seus conhecimentos e suas relações. Compreender essas práticas e aprendizagens socioambientais, com intuito de esclarecer se as comunidades autóctones criam outras formas de produção com o ambiente natural e processos de identificação cultural, diante dos modos globalizantes de homogeneização cultural, são um dos direcionamentos das pesquisas em Educação Ambiental proposta por Tristão (2014) com a qual coadunamos.

\section{Metodologia}

Optamos por realizar uma pesquisa qualitativa na busca da compreensão da relação ambiental do Terena com a natureza. Essa metodologia nos deu possibilidades de pesquisar os fenômenos das relações sociais ocorridos em vários ambientes pois o contexto em que o fenômeno ocorre e do qual faz parte deve ser analisado para ser melhor compreendido, mas para isso o pesquisador precisa perceber o fenômeno a partir do ponto de vista das pessoas envolvidas (GODOY, 1995).

Além de qualitativa, nossa pesquisa foi baseada nas Teorias Pós-Críticas que têm como premissa o comprometimento de estudar e intervir no mundo a fim de modificar o "status quo" (MEYER; PARAíso, 2014). Nossos procedimentos metodológicos na produção de conhecimento objetivaram desconstruir discursos hegemônicos e possibilitar a transformação educacional e social, não nos preocupando em buscar respostas. Com esse olhar buscamos compreender a relação dos indígenas Terena, da aldeia Lagoinha no Município de Aquidauana, Mato Grosso do Sul, com a natureza e como seus saberes podem 
contribuir com a Educação Ambiental, ancorando a pesquisa no método da História Oral que privilegia as histórias contadas pelo grupo pesquisado.

Esse método permite que as pessoas falem livremente expressando sentimentos, permite que contem a história de suas vidas com episódios alegres ou tristes. Segundo Brand (2000) a característica principal do documento de história oral é a recuperação do que o indivíduo entrevistado viveu. Ele ainda destaca que é importante o uso de técnicas de história oral quando a pesquisa é realizada com analfabetos ou povos de cultura oral ou sem escrita, pois é uma forma de integrá-los à história, como, "os povos indígenas [que] devido à sua tradição oral e ao processo de exclusão a que foram submetidos, não conseguiram ser ouvidos pelas fontes escritas e documentais" (BRAND, 2000, p. 197).

Além desse motivo, optamos pela história oral devido ao fato da oralidade ser usada na transmissão de conhecimento, característica forte dos indígenas, visto que, as etnias ancestralmente não possuíam a escrita e o conhecimento era repassado nas gerações pela oralidade, fortemente presente até hoje. Para explorar a história oral optamos pela entrevista não estruturada como ferramenta de pesquisa, pois permite ao pesquisador produzir muitos dados. As entrevistas foram conduzidas com tranquilidade e sem pressa, para deixar o informante à vontade de falar o quanto quiser, de forma fluida e não controlada, sem muitas perguntas (THOMPSON, 1992).

\section{Resultados e discussão}

Originalmente os indígenas apresentavam uma estrutura de sociedade igualitária, onde os membros possuem direitos iguais, não existindo distinção de gênero ou classes. As roças eram propriedades das famílias constituídas de pai, mãe, filhos e tudo que é produzido é dividido conforme o parentesco, a política ou os rituais (SILVA, 1987).

Kauss e Peruzzo (2012, p. 39) ponderam que homens e mulheres tomavam juntos as decisões sobre a coletividade, não existindo o "domínio de poder do gênero masculino, cada qual tinha seu espaço de atuação e não questionavam esses lugares colocados pela tradição". As mulheres possuíam um papel importante em relação às decisões familiares e por mais que o trabalho fosse dividido por idade e sexo, imperava a complementaridade e o diálogo entre homens e mulheres sem sobreposição ou superioridade em relação ao gênero. 
Tudo era organizado entre todos os membros da tribo, inclusive as tarefas do dia-adia eram divididas por idade e por gênero: os homens tinham suas funções, e as mulheres, as delas. A atribuição de tarefas especificas não significava inferioridade ou distinção de poder, eram, simplesmente, tarefas que precisavam ser feitas para o bem de todos (KAUSS E PERUZZO, 2012, p. 34).

Com a colonização, foram submetidos a colonialidade do poder (QUIJANO, 2000), ser, e do saber, impondo outra língua, outra religião, outros cantos, outras danças, outra cultura e com ela a superioridade masculina sobre a feminina. A colonização impactou violentamente indígenas, que foram humilhadas, molestadas e abusadas pelo fato de serem indígenas e mulheres. Com o passar do tempo a colonialidade embranqueceu a cultura indígena e em relação ao gênero, o indígena homem assumiu a identidade do colonizador, e passou a enxergar sua força física como superior, evidenciando essa superioridade na liderança das aldeias e em casa, onde diminuiu o poder de decisão feminina. "Muitas mulheres indígenas se [viram enfrentando] condições injustas impostas pelas sociedades dominantes e posteriormente adotadas por suas próprias comunidades" (PINTO, 2010, p. 2).

Essas mudanças em sua sociedade fizeram com que as mulheres reagissem e passassem a se organizar lutando pelos seus direitos e para serem ouvidas, visto que, possuem um importante papel dentro da sua sociedade como esposa, mãe, educadora, provedora, trabalhadora da terra, comerciante, empresária, entre outras funções.

\footnotetext{
Desta forma as mulheres indígenas organizadas estão criando formas diversas de política cultural, através das quais descentram os discursos de poder sobre a cidadania e a nação, e os discursos hegemônicos do movimento indígena e do feminismo sobre a modernidade e tradição. Num sentido amplo, estão redefinindo o que se entende por política e por empoderamento, desde suas lutas coletivas e desde suas práticas cotidianas (PINTO, 2010, p. 5).
}

Diante disso, entendemos que ao lutar pelo seu espaço, também tenham criado uma dança só de mulheres, visto que os relatos do passado descrevem que as danças eram realizadas pelos dois sexos em conjunto.

Em 1898, Bach presenciou e descreveu 4 danças entre os Terena da região do município de Miranda/MS e aldeia Ipegue no município de Aquidauana/MS (SOCIEDADE CIENTÍFICA ARGENTINA, 1916). Na descrição, as quatro eram dançadas por homens e mulheres, não havendo separação de sexo por dança. Encontramos registros sobre a dança 
exclusivamente masculina, Kohixóti kipaé ${ }^{4}$, a partir do início século 20, enquanto que os registros sobre a dança das mulheres, Sipúterena, datam do fim do século 20.

Entendemos a dança das mulheres como uma forma de expressar a resistência e a força feminina, como veremos adiante.

$\mathrm{Na}$ aldeia Lagoinha localizada na zona rural do Município de Aquidauana/MS, as danças são realizadas em datas comemorativas, como o dia do índio (19 de abril), aniversário da aldeia (04 de dezembro) ou quando recebem visitas importantes e cerimônias religiosas.

Na semana que antecede o dia do índio, iniciam os ensaios das danças, que acontecem geralmente às 19 horas na quadra de esportes da Escola Municipal Indígena Marcolino Lili. Os ensaios ocorrem a noite por ser fresco, o que ameniza o desgaste físico das crianças e senhoras que participam, e para que as mulheres que trabalham durante o dia, possam participar no período noturno. No ano de 2019 , setenta mulheres (entre adultas e crianças) participaram da dança. Após o ensaio da dança das mulheres (Sipúterena) os homens passam a ensaiar.

Encontramos quatro grafias diferentes para a dança das mulheres: Sipúterena, Siputrena, Siputrema, Xiputerena, essas são variações que ocorrem de aldeia para aldeia. Conforme informação da indígena Terena professora e pesquisadora Évelin Tatiane da Silva Pereira a dança também é conhecida por putu putu ${ }^{5}$.

\section{Preparativos que antecedem a dança}

Durante a semana que antecede o dia do índio, na escola, são realizadas atividades especiais, como contação de histórias e mitos por anciões, desenham e pintam grafismos, expõem os resultados das pesquisas realizadas sobre os costumes antigos, a religião, dança, comida e artesanato.

\footnotetext{
${ }^{4}$ Significa dança da ema, mas tem pessoas que também a chamam de dança do bate-pau porque os homens dançam com um pedaço de bambu e batem um no outro em parte da dança.

${ }^{5}$ Palavras que reproduzem o som das batidas do tambor tocado durante a dança e apelidado dessa forma pelos não indígenas.
} 
A pintura do corpo é feita com tinta à base de jenipapo ${ }^{6}$ (Genipa americana L.). 0 fruto verde tem uma substância, a genipina, que possui coloração azul escura ou azul negro, mas perde seu efeito corante depois que amadurece (SOUZA, 2007).

Há várias técnicas de extração da tinta, mas a mais utilizada é ralando o jenipapo verde onde extraem o suco e misturam com pó de carvão. O carvão serve apenas para deixar o líquido mais preto e poder enxergar melhor na hora de desenhar a pele. Segundo os indígenas, quanto mais tempo o suco ficar na pele, mais escura a pintura fica. Essa constatação dos indígenas, se dá pelo fato da genipinina ter "alta estabilidade ao calor, à presença de luz e à mudança de Ph" (BELLÉ, 2017, p. 37), ou seja, o tempo de exposição do pigmento ao calor e a luz solar ajudam na fixação do mesmo na pele.

No corpo as crianças pintam flores de maracujá conforme mostra a figura 01, as mesmas pintadas nas cerâmicas e consideradas femininas. Além das flores de maracujá, as mulheres também pintam grafismos considerados masculinos (figura 02), e outras que misturam as pinturas masculinas e femininas. No rosto obrigatóriamente, segundo as anciãs, devem pintar os circulos concêntricos (figura 03), nas cores branca, vermelha e preta, cores tradicionais do povo Terena.

\footnotetext{
${ }^{6}$ Segundo o dicionário Aurélio a palavra jenipapo tem origem no Tupi-Guarani e significa fruta que serve para pintar
} 
Figura 01: Flor de maracujá

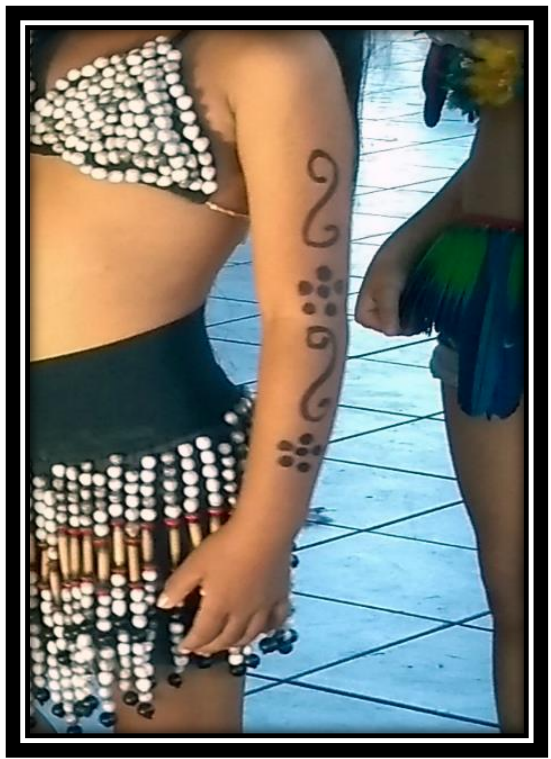

Fonte: Acervo da autora (2019).
Figura 02: Pintura corporal para dança

Sipúterena

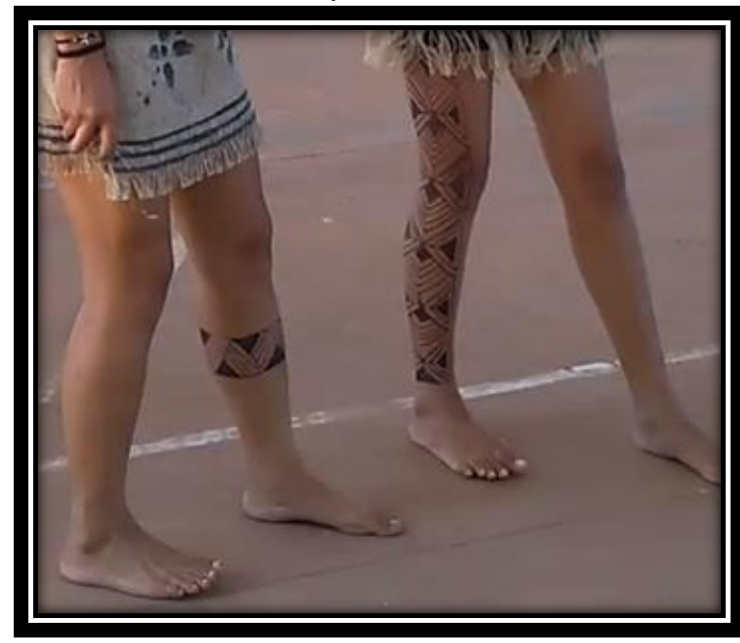

Fonte: Acervo da autora (2019).

Figura 03: Pintura no rosto de círculos concêntricos

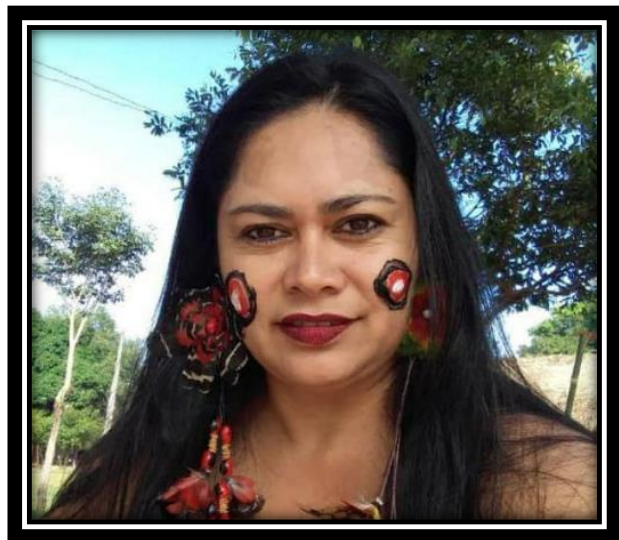

Fonte: Lindomar Lili Sebastião (Rede social, 2019).

A roupa tradicional é feita de juta (figura 05), mas também pode ser usado o algodão cru ou sementes (figura 06). Geralmente fazem um top e uma saia, mas há quem prefira vestidos. A pintura da roupa é realizada na escola que fornece as tintas de tecido nas cores tradicionais, vermelho preto e branco e sob orientação da coordenadora que ensina os significados das cores e dos desenhos. O desenho que parece um triângulo aberto, representam as ocas ou casas das famílias indígenas (figura 05). Os círculos concêntricos, também presentes nas roupas, significam uma aliança, uma união ininterrupta, sem fim entre os povos na promoção da paz. O vermelho representa o sangue derramado nas guerras, o preto significa guerra e luto pelos mortos nas guerras e o branco representa a paz. 
Os adornos usados pelas mulheres são colares de sementes, brincos de penas, tiara e cocar de penas coloridas de todos os tamanhos, braceletes e tornozeleiras (figura 06).

Figura 05: Configuração das posições na dança Sipúterena

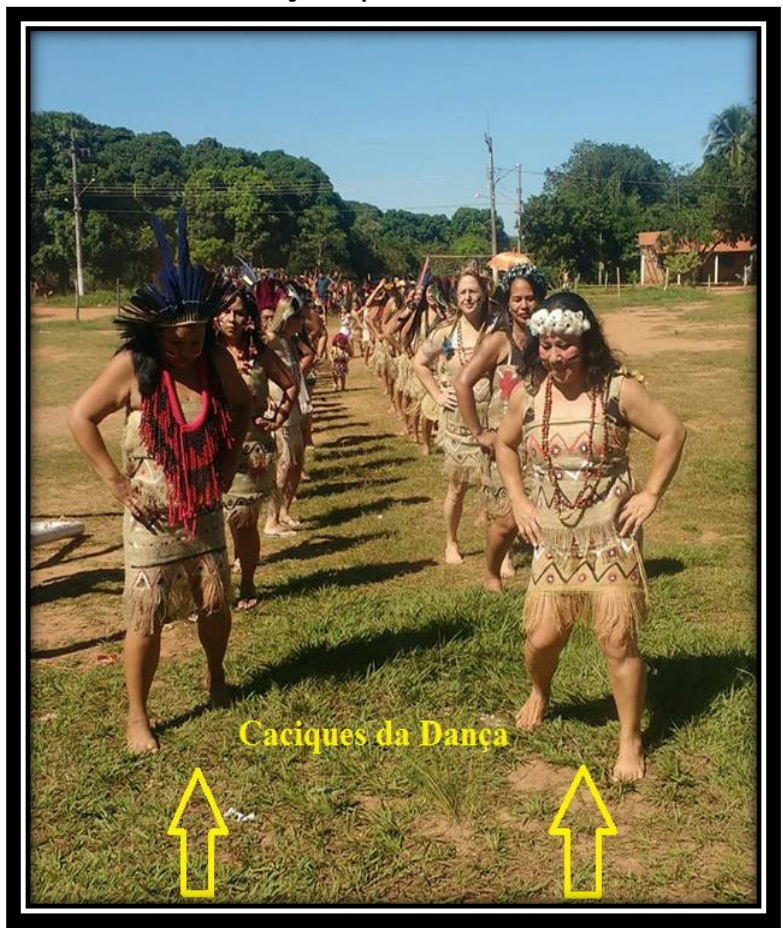

Fonte: Flávio Cecé (Rede social, 2019).

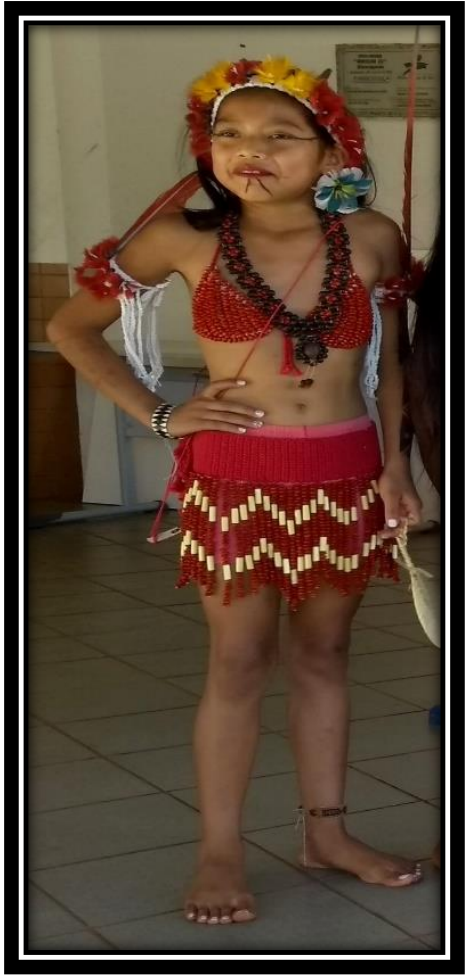

Fonte: Acervo da autora (2019).

Figura 06: Acessórios 
Originalmente a dança das mulheres tem cinco partes, como se fosse uma peça teatral, mas poucas vezes são dançadas integralmente, pois se leva muito tempo para ser executada. Sipúterena é dançada aos pares em duas fileiras (figura 05). Hora os pares dançam juntas e hora se separam, há momentos em que formam um trio. As primeiras duas mulheres da fila são chamadas de caciques da dança (figura 05). A música que as acompanha é tirada de uma flauta de bambu e tambores, tocados pelos homens.

A dança é carregada de fortes cargas simbólicas, valores cognitivos. É uma representação, uma demonstração de alegria um momento de respeito e união para mostrar com orgulho a sua cultura e a resistência feminina. Percebemos que as mulheres se unem para dançar, mesmo aquelas que por ventura tenham algum problema pessoal, nesse momento deixam de lado. Esta união, representada pelos círculos concêntricos simboliza amparo, companheirismo, solidariedade. A dança das mulheres é uma forma de agradecer o presente, o hoje, o fato de estarem vivos, de terem resistido, enquanto muitas outras etnias sucumbiram no processo de colonização. Elas dançam comemorando a vitória, agradecendo a natureza que é considerada a provedora de alimentos, de recursos, a que concebe a vida, como as guerreiras Terena.

Krenak (1996), lembra que muitos não indígenas não conseguem entender suas danças, mas que toda a simbologia de gestos, grafismos e cores possui um significado.

[...] todos esses gestos estão fundados num sentido imemorial, sagrado. Alguns desses movimentos, coreografias se você prestar atenção, ele é o movimento que o peixe faz na piracema, ele é o movimento que um bando de araras faz, organizando o voo, o movimento que o vento faz no espelho da água, girando e espalhando, ele é o movimento que o sol faz no céu, marcando sua jornada no firmamento é também caminho das estrelas, em cada uma das suas estações. Por isso que eu falei a você de um lugar que a nossa memória busca a fundação do mundo, informa nossa arte, a nossa arquitetura, a nosso conhecimento universal (KRENAK, 1996, p. 202).

O professor Seizer, da etnia Terena, acredita que os com movimentos de levantar e abaixar o tronco e balançar os quadris, além de ser uma reverência aos guerreiros recémchegados da guerra ou das partidas de caça e pesca, também seja uma forma das esposas mostrarem sua sensualidade para seus maridos, após um longo período de tempo separados. 
Para Woodword (2000) a representação é construída com práticas de significação e sistemas simbólicos e é por meio disso que os significados são construídos, nos posicionando como sujeitos. "É por meio dos significados produzidos pelas representações que damos sentido à nossa experiência e àquilo que somos" (WOODWORD, 2000, p. 17). Ou seja, as danças têm grande representatividade para o Terena, por conta dos significados que foram construídos ao longo do tempo.

Todo esse significado é ensinado pelas anciãs às crianças com muita atenção e carinho. "Todo ensinamento repassado pelos anciões[ãs] ficarão vivos em cada memória destes jovens onde por sua vez deverá também ser repassado para os[as] futuros[as] guerreiros[as] com intuito de torná-los[as] grandes líderes [...]” (ALVES, 2016, p. 25).

Percebemos que ensinar a dança faz parte do processo de resistência da memória ${ }^{7}$, pois ela lembra o que tiveram que fazer e passar para estarem aqui hoje. E para se fazerem presentes, as Terena tiveram que se reelaborar, ressignificar, apropriar, incorporar, e compreender que a etnia em si é única, e que mesmo atravessados por relações outras, produzem características próprias do povo Terena (SEIZER DA SILVA, 2016).

Além das questões sociais, observamos as questões ambientais e a utilização dos recursos, visto que $80 \%$ dos materiais usados pelas mulheres na dança tem origem na natureza, como sementes, penas, fibras e tinta. Existe uma relação íntima com dos Terena com a natureza, com o ambiente em que vivem. Para Fernando Moreira, perguntamos sobre a relação da sua cultura com a natureza, e ele nos respondeu que "a cultura indígena nunca foi entendida pelas outras culturas quando se fala em sobrenatural, sobre natureza, estamos (nós índios) ligados à natureza que até nós não temos como explicar, para entender é preciso viver aqui no meio da gente". Os indígenas, enxergam que sua sobrevivência depende dos cuidados com a natureza.

Kopenawa explica a dinâmica da floresta ao falar da fertilidade que a faz crescer e amadurecer os alimentos que sustentam os animais e seres humanos, se referindo ao ciclo da vida e da matéria mostrando a conexão existente entre os elementos que compõem a Natureza (KOPENAWA; ALBERT, 2015).

\footnotetext{
${ }^{7}$ Resistência da memória é uma expressão usada por Naine Terena de Jesus em sua dissertação de mestrado em 2007.
} 
$\mathrm{Na}$ ecologia, aprendemos que nenhum ser é independente do outro, nem das porções que não tem vida, como a água, a terra, o fogo, ou o ar. Os humanos são ecodependentes dos ecossistemas e o mal que acontece em um, recairá sobre os outros. Somos elos intrínsecos de uma Terra que carece de toda sua extensão para que continue existindo (SATO; SANTOS; SÁNCHEZ, 2020, p. 7).

Kopenawa, Sato, Santos e Sanches se utilizam de palavras diferentes para dizerem a mesma coisa. Para que tudo continue existindo todos os elos precisam de proteção. É muito importante destacar que os ambientes "ocupados por essas comunidades são menos modificados e degradados que as áreas adjacentes [...] suas economias e tecnologias tradicionais são, em geral, ambientalmente apropriadas" (DIEGUES, 2000, p. 239), devido a sua sintonia com o ambiente. Essa sintonia com o ambiente se mantém presente na memória dos Terena, mesmo não possuindo mais seu território original. Não escolheram viver assim, mas foram obrigados a mudar para sobreviver. Percebemos que mesmo interculturalizados, estando tão próximos das cidades, e sem suas matas nativas originais, os indígenas Terena da aldeia Lagoinha, não perderam essa visão de natureza descrita por Kopenawa.

\section{Artesanato}

Verificamos a consciência ecológica dos artesãos que fazem os braceletes, tornozeleiras e cocares de penas. Na maioria dos casos utilizam penas de galinha coloridas para fazer brincos, mas os cocares são feitos a partir de penas de papagaios e araras, pois, é parte da identidade do Terena. Denise Augusto, que nos contou que aprendeu o artesanato com seu pai e que também a ensinou o respeito pela mãe natureza. Ela sente a necessidade de pedir autorização da natureza para fazer coletas de sementes, de fibras ou de penas. Agradece o chão, as plantas e os animais porque precisa desse recurso para a sua sobrevivência, demonstrando para a mãe natureza tem respeito por tudo que ela fornece.

Pois tudo que é vivo, tudo que é natural tem uma mãe, as árvores são as mães das sementes, as galinhas são as donas das penas, assim tenho essa necessidade porque aprendi que precisamos ter esse respeito e autorização para utilização desses recursos (Entrevista realizada com artesã Denise Augusto em novembro de 2019). 
Para Souza et al. (2015), “o saber ecológico e os costumes tradicionais indígenas de gestão dos recursos naturais apresentam soluções baseadas não somente em generalidades de experimentação e observação, mas enraizadas em sistemas locais de valores e significados", e quando Denise fala em chão, árvores e animais, percebemos os valores e significados e que ela conhece a relação entre os seres e o ambiente físico, interligados pela teia alimentar e ciclos biogeoquímicos que reestabelece naturalmente a vida na Terra.

Guimarães e Medeiros (2016) ponderam que os povos indígenas têm a compreensão de sua dependência da natureza, tanto física como cosmológica assim como "se sentem e são parte integrante da mesma, e em função dessa forma de ser natureza, desenvolvem formas de uso racional da mesma" (GUIMARÃES; MEDEIROS, 2016, p. 56).

Marcelo Cecé (39 anos) músico e Délio Delfino (60 anos) professor, nos explicou como os Terena, entendem por Natureza:

A natureza é algo essencial, o índio ele tem uma ligação muito forte com a natureza né, tanto como fonte de alimento, remédio, entendeu? A natureza para nós é isso, é da onde tiramos tudo, hoje mudou muito, mas no passado, desde da moradia era extraído diretamente... diferente de hoje que é comprado material de construção na cidade né, mas antigamente desde da casa da natureza, a própria cama, colchão, o fogão, entendeu? $\mathrm{O}$ alimento em si, remédio quando precisava, então é tudo extraído da natureza (Entrevista realizada com Marcelo Cecé, fevereiro de 2020).

Para nós a natureza é a terra, porque é muito sagrada, por que dali tiramos nossa alimentação e é bem diferente da sociedade que se preocupa em ganhar dinheiro encima da natureza, aí vemos grande quantidade de matas derrubadas causando prejuízo para a natureza. A natureza pra mim é isso, mas as pessoas com imensidão de lavouras pensando na finança, no seu enriquecimento dentro da natureza. Nós temos lavoura não em grandes quantidades, mas em pequena quantidade, mas para consumo e sustentar nossas famílias. Planta-se de tudo, a gente precisa da natureza, da terra, nós precisamos da natureza, da terra para viver. A natureza pra mim, ou seja, para o povo terena é muito forte, a natureza para nós é a vida do próprio povo terena, por que a natureza são as matas, os rios, a própria pessoa como ser, e esse ser antigamente precisava da natureza, principalmente para curar doenças, antigamente não tinha médico como temos hoje, então íamos para a natureza, pois os antepassados ensinavam e eles sabiam sobre os remédios dentro da própria natureza. Por isso que falamos que a natureza é muito forte para nós, então dentro da natureza há muitas espécies de plantas que serve para curar a enfermidade, mas hoje em dia não procuramos saber, pesquisar, estudar, não procuramos (se referindo aos jovens) os anciões que ainda está sobre as nossas aldeias, se continuar assim a tendência é acabar e não ter mais história sobre o que é a natureza (Entrevista realizada com Délio Delfino, março de 2019, grifo nosso).

Mesmo vivendo em outras condições o senhor Délio ainda carrega consigo os saberes ancestrais repassados para ele, pois estão gravados em sua memória, "codificado na 
bagagem tradicional transmitida e refinada de geração em geração" (DIEGUES, 2000, p. 239). Délio ainda frisa que enxergam a Natureza como sagrada, "bem diferente da sociedade que se preocupa em ganhar dinheiro encima da natureza", se referindo à sociedade capitalista. O que Délio denuncia é corroborado pela professora Michèle Sato: "a humanidade se move pela busca do desenvolvimento, geralmente material, e que o Capitalismo frenético seduz pessoas do mundo inteiro a consumir o planeta" (SATO, 2018, p. 210). Outro ponto a ser destacado na fala dele, é a inclusão do ser humano como pertencente à Natureza, e que no passado dependia apenas dos recursos in natura para sobreviver, enquanto que a cultura ocidental separou o ser humano da Natureza.

Embora não conheçam o conceito ocidental da palavra Natureza, no discurso reconhecemos o quanto eles entendem do assunto e como é diferente da visão ocidental. Depois de nos dizer o que entendia por Natureza, perguntamos ao senhor Leopoldo da Silva (artesão de 64 anos) se existia uma palavra em Terena que a representasse. Ele disse, "mêum, significa mundo, mas tudo, nós, as plantas, o solo, os animais, todos os seres e um depende do outro" (grifo nosso). Dessa forma, mêum é o mundo Terena, a Natureza que envolve todos, e quando ele fala sobre um depender do outro, está se referindo ao que entendemos na Biologia como cadeia e teia alimentar, assim como as relações intra e interespecíficas. Reforço novamente que recorro à Biologia na busca de compreender o olhar indígena sobre o ambiente e privilegiar o diálogo entre ciência ocidental e ciência indígena.

Essa mesma palavra mêum encontramos na resposta do seu Antenor Augusto da Silva (artesão de 59 anos) quando Ihe perguntamos o que era Natureza.

\footnotetext{
Posso responder no idioma? Konokoati koyonoyea koane kátarakea ûti ra mêum vovoku kuteati tikotihiko maka motovâti enoiyea káxe vovea ra Poké'e. Enomone ko'omixone ûti enepo'oxo vihuinovamaka vo'oku enomone veyoponeamaka nika ûti enomonemaka kuti'ino apêti numíkuxoti Koane ihókoti xapa viyénoxapa. Anekomaka uhe'ekotinoe coxe'u tikoti motovâti vitukea vovoku. koati vomixone ra mêum kuti kixoa uti vêno ${ }^{8}$. (Falou em Terena e depois traduziu). Natureza é as matas e nós tem que cuidar da natureza das matas, das árvores para que nós possamos viver muitos anos de vida aqui no mundo. A mata são a nossa vida, nossa sobrevivência da caça, da pesca, das madeiras que nós utilizamos pra ter a nossa casa, essa é a nossa vida. A mata são a mãe que nós temos. A minha ligação com a natureza é muito forte, mas tem gente que não! A gente que trabalha com mel, a gente tem muito carinho pelas matas, porque se não tiver as matas, as abelhas não
}

8 Transcrito em Terena por Délio Delfino. 
vão vir aqui né. Em outros municípios você só vê veneno que acaba matando as abelhas (Entrevista realizada com Antenor Augusto, novembro de 2019).

Os senhores Antenor e Leopoldo, usaram a palavra mêum para descrever a Natureza. Seu Antenor ainda se referiu a ela como a mãe que fornece tudo para a sobrevivência. A ligação dele com a mãe Natureza é forte por ser produtor de mel, e para que as abelhas produzam mel precisam das matas, mas os venenos utilizados na agricultura matam as abelhas. Na fala dele podemos perceber que ele conhece as relações entre os seres vivos, “eles são familiares com as leis da natureza" (DIEGUES, 2000, p. 240).

Segundo Diegues (2000) originalmente não existe em seu vocabulário tradicional as palavras conservação e ecologia. Buscamos saber entre os anciões se havia essas palavras entre os Terena e também descobrimos que não, os que falam em conservação aprenderam na educação escolar. Embora as palavras não existam, o conceito, o entendimento sobre, existe.

A respeito do uso racional dos elementos fornecidos pela natureza, trazemos aqui os irmãos Ailton, Berenice e Airson que trabalham com artesanato. Embora Ailton e Airson tenham um emprego convencional, nas horas vagas fazem artesanato, já Berenice vive do artesanato. Eles fazem brincos, colares, tiaras, abanicos, cocares, arco e flecha, braceletes e tornozeleiras. Utilizam, sementes de várias espécies e fibras de buriti (Mauritia flexuosa), palmeira do cerrado de grande porte que possui folhas dispostas em leque. Sementes são coletadas, folhas de palmeiras são cortadas e a madeira é retirada de maneira que não agrida a natureza.

Os irmãos possuem uma consciência ambiental passada de pais para filhos e Airson, graduado em Turismo, tem conhecimento de gestão ambiental e assegura que o recurso é retirado de forma sustentável. Para Guimarães e Medeiros (2016, p. 55), os indígenas:

[...] manejam os recursos naturais de suas áreas ocupadas imemorialmente de maneira branda, aplicando estratégias de uso dos ambientes naturais de forma que não alteraram os princípios de funcionamento dos mesmos, da mesma forma que esses usos não colocaram em risco as condições de reprodução desses ambientes (GUIMARÃES; MEDEIROS, 2016, p. 55).

O reconhecimento desses outros saberes, Santos (2008) chama de ecologia de saberes e a compreende como um conjunto de epistemologias da diversidade, a prática de saberes. 
A ecologia de saberes assenta na interdependência complexa entre os diferentes saberes que constituem o sistema aberto do conhecimento em processo constante da criação e renovação. O conhecimento é interconhecimento, é reconhecimento, é autoconhecimento (SANTOS, 2008, p. 157).

A ecologia dos saberes se situa em um contexto cultural ambíguo, porque enquanto o reconhecimento da diversidade sociocultural favorece o reconhecimento da diversidade epistemológica de saber no mundo, todas as epistemologias também partilham as premissas culturais do seu tempo, sendo a crença na ciência como uma forma de conhecimento válido, a mais consolidada (SANTOS, 2008). Concordamos com Sato e Passos (2009, p. 44) que "a cultura talvez seja a chave de compreensão dos dilemas socioambientais desde que dela emanem as escolhas históricas da civilização humana".

Fundamentada nessas compreensões que a Educação Ambiental (EA) tem produzido narrativas de valorização dos saberes das comunidades tradicionais. A Educação Ambiental é um processo onde os indivíduos constroem valores sociais, habilidades e conhecimento para pensar a conservação ambiental para uso comum e sustentável pela população (BRASIL, 1999). Segundo Carvalho (2008) a visão socioambiental direciona-se para a racionalidade complexa e interdisciplinar pensando o ambiente como campo de interações entre cultura, sociedade e parte biótica e abiótica. Nesse caso a presença humana é vista como integrante à teia de relações da vida, interagindo no social, natural e cultural.

Para Hall (2003, p. 141-2) não é possível pensar a natureza independente da cultura, pois cultura é "algo que entrelaça todas as práticas sociais, e essas práticas, por sua vez, como uma forma comum de atividade humana: como práxis sensual humana, como a atividade através da qual homens e mulheres fazem a história". Embora Hall se refira à natureza humana, me atrevo a relacionar e pensar essa natureza como o meio ambiente, pois a relação humana com o meio ambiente depende também de sua cultura. Se a cultura é baseada nas ideias da modernidade e do capitalismo, com certeza os recursos ambientais serão explorados até o máximo que as leis permitem, mas se a cultura é baseada no pensamento de interdependência e que o ser humano faz parte dessa natureza, então essa relação pode se tornar sustentável.

Já colhemos os frutos podres da nossa cultura Ocidental moderna capitalista, e baseados nessas consequências voltamos os olhos para culturas outras, na busca de respostas, na busca de formas sustentáveis de relações entre a sociedade e natureza que 
resulte numa vida equilibrada e justa em todos os sentidos para todos os habitantes do planeta.

\section{Considerações Finais}

Observamos uma diversidade de conhecimentos, saberes, e epistemologias nas relações entre os indígenas e natureza. Eles percebem os lugares como ambientes produtores de ensinamentos de pensar e estar no mundo. As comunidades tradicionais observaram e compreenderam a biodiversidade com a qual conviviam, e por meio dessa compreensão desenvolveram práticas e técnicas sobre os recursos. Esses saberes são o resultado de traduções para sobrevivência que influenciaram sua cultura e seu ambiente.

Consideramos, à luz do Grupo Modernidade/Colonialidade, que as narrativas contadas pelas comunidades tradicionais de suas danças e artesanato, são valiosas, no sentido de compreender o respeito pelas relações e inter-relações de interdependência com os outros seres vivos e não vivos (físicos e espirituais). É uma lógica diferente a sua visão de mundo e de vida, que promove a sustentabilidade em seus espaços de vivência e convivência, seus lugares de cultura.

Suas práticas culturais e pedagógicas estão cheias de conceitos biológicos e ecológicos que podemos empregar na discussão de uma Educação Ambiental decolonial. Decolonial no sentido de entender que a nossa cultura e nossa forma de entender o mundo (ocidental, hegemônico) não é única e nem a melhor. Essas práticas culturais são uma forma de resistência e fortalecimento de suas identidades.

A Educação Ambiental é entendida como um processo onde os indivíduos constroem valores sociais, habilidades e conhecimentos para pensar a conservação ambiental para uso comum e sustentável pela população, e essas características observamos no estilo de vida dos Terena, dessa forma, afirmamos que nós educadores ambientais precisamos considerar que os saberes tradicionais podem contribuir nas reflexões sobre como entendemos e enxergamos a natureza e o quanto nossas ações culturais estão interferindo negativamente no ambiente.

Dessa forma, como educadores ambientais, devemos olhar para a cultura indígena como fonte de aprendizagem, na construção de uma EA decolonial, um espaço dialógico e 
de inclusão que não tem objetivo de julgar, mas sim compreender a pluralidade de pensamentos outros, de culturas outras, em colaboração com a manutenção e sustentabilidade planetária.

\section{Referências}

ALVES, Gerson Pinto. O protagonismo da Escola Polo Indígena Terena Alexina Rosa Figueiredo, da Aldeia Buriti, em Mato Grosso do Sul, no processo de retomada do território da terra Indígena Buriti. 2016. Dissertação (Mestrado em Educação) Universidade Católica Dom Bosco, Campo Grande, 2016.

SOCIEDADE CIENTífICA ARGENTINA. Tomo LXXXII, Segundo Semestre, 1916, Buenos Aires. Anales de la Sociedad Científica. Buenos Aires: Imprenta y Casa Editora de Coni Hermanos, 1916. 312 p. BACH, J. Datos sobre los Indios Terinas de Miranda.

BHABHA, Homi K. O local da cultura. Belo Horizonte: UFMG, 1998.

BALLESTRIN, Luciana. América Latina e o giro decolonial. Revista Brasileira de Ciência Política, Brasília, DF, n. 11, p. 89-117, 2013.

BELLÉ, Anelise Stein. Extração de genipina a partir do Jenipapo (Genipa americana Linnaeus) para imobilização de enzimas. 2017. Dissertação (Mestrado em Ciência e Tecnologia de Alimentos) - Universidade Federal do Rio Grande do Sul, Porto Alegre, RS, 2017. Disponível em:

https://lume.ufrgs.br/bitstream/handle/10183/172109/001056635.pdf?sequence=1\&isAllo wed=yAcesso em: 20 maio 2020.

BRAND, Antônio. História oral: perspectivas, questionamentos e sua aplicabilidade em culturas orais. História Unisinos, São Leopoldo, v. 4, n. 2, p. 195-227, 2000.

BRASIL. Lei no 9.795, de 27 de abril de 1999. Dispõe sobre a educação ambiental, institui a Política Nacional de Educação Ambiental e dá outras providências. Brasília, DF, 1999. Disponível em: http://www.planalto.gov.br/ccivil 03/LEIS/L9795.htm. Acesso em: 11 novembro 2018.

CARVALHO, Isabel Cristina de Moura. Educação ambiental: a formação do sujeito ecológico. 3. ed. São Paulo: Cortez, 2008.

DIEGUES, Antônio Carlos S. Etnoconservação da natureza: enfoques alternativos. In: DIEGUES, Antônio Carlos S. Etnoconservação: novos rumos para a proteção da natureza nos trópicos. São Paulo: USP, p. 1-46, 2000.

GODOY, Arilda Schmidt. Pesquisa qualitativa: tipos fundamentais. Revista de Administração de Empresas, São Paulo, v. 35, n. 3, p. 20-9, 1995.

GUIMARÃES, Mauro; MEDEIROS, Heitor Queiroz de. Outras epistemologias em Educação Ambiental: o que aprender com os saberes tradicionais dos povos indígenas. REMEA Revista Eletrônica do Mestrado em Educação Ambiental, Rio Grande, edição especial, p. 5067, jul. 2016. 
HALL, Stuart. Da diáspora: identidades e mediações culturais. Organização Liv Sovik; Tradução Adelaine La Guardia Resende. Belo Horizonte: Editora UFMG; Brasília, 2003.

HALL, Stuart. A centralidade da cultura: notas sobre as revoluções culturais do nosso tempo. Educação \& Realidade, Porto Alegre, RS, v. 22, n. 2, p. 15-46, 1997. Originalmente publicado in: THOMPSON, Kenneth (org.). Media and cultural regulation. Inglaterra. Tradução Ricardo Uebel, Maria Isabel Bujes e Marisa Vorraber, Costa. Cap. 5, 1997.

JESUS, Naine Terena. Kohixití-kipaé, a dança da ema - memória, resistência e cotidiano Terena. 2007. Dissertação (Mestrado em Arte) - Universidade de Brasília, Brasília, 2007.

KAUSS, Vera Lucia T.; PERUZZO, Adriana. A inserção da Mulher Indígena Brasileira na Sociedade Contemporânea através da Literatura. Espaço Ameríndio. Porto Alegre, v. 6, n. 2, p. 32-45, jul./dez. 2012. Disponível em

https://seer.ufrgs.br/EspacoAmerindio/article/view/31868/23619. Acesso em: 03 maio 2021

KOPENAWA, Davi; ALBERT, Bruce. A queda do céu: palavras de um xamã yanomami.

Tradução de Beatriz Perrone-Moisés; prefácio de Eduardo Viveiros de Castro. 1. ed. São Paulo: Companhia das Letras, 2015.

KRENAK, Ailton. Antes, o mundo não existia. In: NOVAES, Adauto. Tempo e história. São Paulo: Companhia das Letras, 1996.

MEYER, Dagmar Estermann; PARAísO, Marlucy Alves (org.). Metodologias de pesquisa póscrítica em educação. 2. ed. Belo Horizonte: Mazza Edições, 2014.

PINTO, Alejandra A. Reinventando o feminismo: as mulheres indígenas e suas demandas de gênero. Fazendo Gênero 9: Diásporas, Diversidades, Deslocamentos. 23 a 26 de agosto de 2010. Disponível em http://www.fg2010.wwc2017.eventos.dype.com.br/resources/anais/1276200140 ARQUIVO ApresentFazendoGeneroAleword.pdf. Acesso em 01/05/2021.

QUIJANO, Aníbal. Colonialidad del poder y clasificacion social. Journal of World-Systems Research, [S.I.], v. 11, n. 2, p. 342-86, 2000.

SANTOS, Boaventura de Sousa. A gramática do tempo: para uma nova cultura política. 2. ed. São Paulo: Cortez, 2008.

SATO, Michèle. Pot-pourri da ecologia de resistência. In: SORRENTINO, Marcos (org.). Educação ambiental e políticas públicas: conceitos, fundamentos e vivências. 2. ed. Curitiba: Appris, p. 202-11, 2018.

SATO, Michèle; PASSOS, Luiz Augusto. Arte-educação-ambiental. Ambiente \& Educação, Rio Grande, v. 14, n. 1, p. 43-59, 2009.

SATO, Michèle; SANTOS, Déborah M.; SÁNCHEZ, Celso. Vírus: simulacro da vida? Rio de Janeiro: GEA-SUR, UNIRIO; Cuiabá: GPEA, UFMT, 2020.

SEIZER DA SILVA, Antonio Carlos. Kalivôno Hikó Terenôe: sendo criança indígena Terena do século XXI - vivendo e aprendendo nas tramas das tradições, traduções e negociações. 2016. Tese (Doutorado em Educação) - Universidade Católica Dom Bosco, Campo Grande, 2016. 
SILVA, Aracy L. Nem taba nem oca: uma coletânea de textos à disposição dos professores. In: SILVA, Aracy L. A questão indígena na sala de aula subsídios para professores de $1^{\circ}$ e $2^{\circ}$ graus. São Paulo: Brasiliense, 1987.

SILVA, Tomaz Tadeu da. Documentos de identidade uma introdução às teorias do currículo. 2. ed. Belo Horizonte: Autêntica, 2004.

SOUZA, Ana Hilda Carvalho de; LIMA, Alexandrina Maria de Andrade; MELLO, Marco Aurélio Anadem; OLIVEIRA, Elialdo Rodrigues de. A relação dos indígenas com a natureza como contribuição à sustentabilidade Ambiental: uma revisão da literatura. Revista Destaques Acadêmicos, Lajeado, v. 7, n. 2, p. 88-95, 2015.

SOUZA, Cilene Nascimento. Características físicas, físico-químicas e químicas de três tipos de jenipapos (Genipa americana L.). 2007. Dissertação (Mestrado em Produção Vegetal) Universidade Estadual de Santa Cruz, Ilhéus, 2007.

THOMPSON, Paul. A voz do passado: história oral. Tradução Lólio Lourenço de Oliveira. São Paulo: Paz e Terra, 1992.

TRISTÃO, Martha. A Educação Ambiental e o pós-colonialismo. Revista Educação Pública, Cuiabá, v. 23, n. 53/2, p. 473-89, 2014.

WALSH, Catherine. Interculturalidade crítica e pedagogia decolonial: in-surgir, re-existir e reviver. In: CANDAU, Vera Maria (org.). Educação intercultural na América Latina: entre concepções, tensões e propostas. Rio de Janeiro, p. 12-43, 2009.

WOODWARD, Kathryn. Identidade e diferença: uma introdução teórica e conceitual. In: SILVA, Tomaz Tadeu (org.). Identiade e diferença: a perspectiva dos estudos culturais. Petrópolis, RJ: Vozes, 2000. p. 7-72. Disponível em:

http://diversidade.pr5.ufri.br/images/banco/textos/SILVA Identidade e Diferen\%C3\%A7a.pdf. Acesso em: 01 fevereiro 2020. 